\title{
Liver venous deprivation: a bright future for liver metastases - but what about hepatocellular carcinoma?
}

\author{
Boris Guiu $^{1}$, Astrid Herrero ${ }^{2}$, Fabrizio Panaro ${ }^{2}$ \\ ${ }^{1}$ Department of Radiology, St-Eloi University Hospital, Montpellier, France; ${ }^{2}$ Department of HBP Surgery \& Transplantation, St-Eloi University \\ Hospital, Montpellier, France \\ Correspondence to: Prof. Boris Guiu, MD, PhD. Department of Radiology (Head), St-Eloi University Hospital, 80 Avenue Augustin Fliche, 34295 \\ Montpellier, France. Email: B-guiu@chu-montpellier.fr.
}

Submitted Jan 10, 2021. Accepted for publication Mar 01, 2021.

doi: $10.21037 / \mathrm{hbsn}-21-7$

View this article at: http://dx.doi.org/10.21037/hbsn-21-7

Liver venous deprivation (LVD) refers to the percutaneous procedure aiming to simultaneously abrogate both portal inflow and hepatic venous outflow to accelerate liver regeneration of the future liver remnant (FLR), which limits patient drop-out from resection due either to insufficient FLR or tumor progression. Some authors have designated the exact same technique under the acronym RASPE (Radiological Simultaneous Porto-hepatic Vein Embolization) (1) while others reported on 'double embolization' for designating portal vein embolization (PVE) and proximal embolization of one hepatic vein, keeping patent distal venous branches and veno-venous collaterals (2).

Four monocentric studies comparing LVD to PVE were published in 2020 (1-4). Despite technical variations, these reports are aligned towards greater FLR regeneration after LVD, both in terms of volume $(1,2,4)$ and function (3). In our series (29 LVD vs. 22 PVE), we reported a 54\% increase in FLR function (99m Tc-mebrofenin scintigraphy) as early as 7 days after LVD, which is unprecedented for a liver preparation technique. Importantly, these functional results only concerned non-cirrhotic patients.

Hepatocellular carcinoma (HCC) is the third leading cause of cancer death worldwide. Hepatic resection is the only curative option for patients with large HCC but most of them have underlying chronic liver disease or cirrhosis, and consequently a high-risk for post-hepatectomy liver failure (PHLF), morbidity and mortality. In this context, the adequacy of FLR for resection is a major consideration.

After resection, cirrhotic liver regenerates at a slower rate (around 50\%) and to a lesser extent than normal liver (5).
After PVE, similar results (median FLR increase at 16\% $v s .9 \%$ in normal $v s$. cirrhotic livers) have been reported (6) leading to consider that post-PVE assessment should rather be performed later (6-8 weeks) in cirrhosis. The risk of tumor progression during this sometimes long-lasting post-PVE period led to propose a sequential approach by transarterial chemoembolization (TACE) followed by PVE several weeks later. In addition to tumor control, this strategy was shown to moderately increase the degree of hypertrophy of the FLR (7). Associating liver partition and portal vein ligation (ALPPS) has also been proposed in HCC and exhibits similar morbidity/mortality rates compared to PVE in recent series coming from expert centers (8). Of note, the percentage of FLR volume gain was significantly lower after ALPPS in patients with cirrhosis $v$. chronic liver disease (32.5\% vs. $52.7 \%$, respectively). This quite disappointing FLR gain after ALPPS is accompanied by an even lower FLR functional gain: in 9 patients followed by $99 \mathrm{mTc}$-mebrofenin scintigraphy, mean increase in FLR function was only $+15 \%$ (range: $-27-44.7 \%$ ) and 4 patients even presented no significant functional change (8). Therefore, LVD is worth exploring in the context of HCC and particularly in cirrhosis.

Unfortunately, data on LVD in cirrhotic patients are scarce. In the five most recent studies, cirrhotic patients were excluded in two $(1,3)$, not treated by LVD in one (4) and were very few $(n=2-3)$ in the others $(2,9)$. Regrettably, no outcome data were reported in this subgroup of patients, even though no specific safety concerns were raised. Some data were not shown, for example ten patients underwent TACE followed by bi-embolization but were not included 
in the comparative study by Le Roy et al. (2), unfortunately.

Compared to PVE alone, LVD is supposed to, induce more damage to the embolized liver and thus drive increased contralateral liver regeneration and counteract persistent minute portal inflow that may occur after incomplete or too proximal PVE (10). When PVE is complete, increased hepatic arterial inflow occurs owing to the hepatic arterial buffer response. Occlusion of hepatic venous outflow in a context of PVE decreases the hepatic arterial inflow because of the limited outflow route (10). Reduced (rather than interrupted) arterial inflow certainly prevents the risk of severe liver/bile-duct ischemia with abscess formation. Such a complication has never been observed so far. In cirrhosis, chronic hyperarterialization of the liver and hypertrophy of the peri-biliary plexus should be able to protect even more against ischemic complications. There is probably nothing to worry about.

However, occluding the outflow (in addition to PVE) in cirrhosis is likely to increase portal hypertension, and here probably lies the major safety concern (10). Reassuring data on portal pressure in LVD are coming from Kobayashi et al. (4): portal pressure increased from 9 to $13 \mathrm{mmHg}$ in LVD [cirrhosis $(n=0)$, fibrosis $(n=8)$, no fibrosis $(n=14)$ ] whereas it increased from 10 to $13 \mathrm{mmHg}$ in PVE [cirrhosis $(\mathrm{n}=1)$, fibrosis $(\mathrm{n}=9)$, no fibrosis $(\mathrm{n}=18)]$. In this study, no significant difference was noted in the increase in portal pressure after LVD vs. PVE. In an older study published by the same author (11), portal pressure in cirrhosis/ advanced fibrosis after PVE increased from 8 to 10.1 $\mathrm{mmHg}$, suggesting a comparable increase whether the liver be cirrhotic or not. In the absence of any specific data, we can assume that the increase in portal pressure should be $\sim 4 \mathrm{mmHg}$ after LVD in cirrhosis. Caution should probably be exercised in patients with borderline portal pressure (i.e., $>11 \mathrm{mmHg}$ ). From a practical point of view, systematic measurement of portal pressure immediately after portal access should help to decide between PVE and LVD. Non-invasive measurements such as liver transient elastography or surface nodularity might also have a role not only to select good candidates to resection but also to decide which technique to apply (PVE, LVD, ALPPS, ...) in these patients. Finally, no case has been reported so far with extended LVD (i.e., embolization of both right and middle hepatic veins in addition to PVE) in the context of cirrhosis. Greater concerns about portal hypertension-as well as venous congestion of at least part of segment IV resulting from the occlusion of middle hepatic vein-justify not performing extended LVD in cirrhosis outside clinical trials.

It is much too early to imagine the place of LVD in
HCC but safety is certainly ensured in cirrhotic patients with normal portal pressure, provided only one hepatic vein be occluded. We strongly encourage teams used to LVD in other indications to publish their results in cirrhosis. One randomized trial (HYPER-LIV02) should start in France in 2021 allowing the inclusion of cirrhotic patients. Let us hope for our HCC patients that the future of LVD will be as bright as it seems to be for liver metastases.

\section{Acknowledgments}

The authors thank Sandrine Guiu for revising the English. Funding: None.

\section{Footnote}

Provenance and Peer Review: This article was commissioned by the editorial office of Hepatobiliary Surgery and Nutrition. The article did not undergo external peer review.

Conflicts of Interest: All authors have completed the ICMJE uniform disclosure form (available at https://hbsn. amegroups.com/article/view/10.21037/hbsn-21-7/coif). Dr. FP and Dr. BG serve as the unpaid editorial board members of Hepatobiliary Surgery and Nutrition. Dr. AH has no conflicts of interest to declare.

Ethical Statement: The authors are accountable for all aspects of the work in ensuring that questions related to the accuracy or integrity of any part of the work are appropriately investigated and resolved.

Open Access Statement: This is an Open Access article distributed in accordance with the Creative Commons Attribution-NonCommercial-NoDerivs 4.0 International License (CC BY-NC-ND 4.0), which permits the noncommercial replication and distribution of the article with the strict proviso that no changes or edits are made and the original work is properly cited (including links to both the formal publication through the relevant DOI and the license). See: https://creativecommons.org/licenses/by-nc-nd/4.0/.

\section{References}

1. Laurent C, Fernandez B, Marichez A, et al. Radiological Simultaneous Portohepatic Vein Embolization (RASPE) Before Major Hepatectomy: A Better Way to Optimize Liver Hypertrophy Compared to Portal Vein 
Embolization. Ann Surg 2020;272:199-205.

2. Le Roy B, Gallon A, Cauchy F, et al. Combined biembolization induces higher hypertrophy than portal vein embolization before major liver resection. $\mathrm{HPB}$ (Oxford) 2020;22:298-305.

3. Guiu B, Quenet F, Panaro F, et al. Liver venous deprivation versus portal vein embolization before major hepatectomy: future liver remnant volumetric and functional changes. Hepatobiliary Surg Nutr 2020;9:564-76.

4. Kobayashi K, Yamaguchi T, Denys A, et al. Liver venous deprivation compared to portal vein embolization to induce hypertrophy of the future liver remnant before major hepatectomy: A single center experience. Surgery 2020;167:917-23.

5. Yamanaka N, Okamoto E, Kawamura E, et al. Dynamics of normal and injured human liver regeneration after hepatectomy as assessed on the basis of computed tomography and liver function. Hepatology 1993;18:79-85.

6. Farges O, Belghiti J, Kianmanesh R, et al. Portal vein embolization before right hepatectomy: prospective clinical trial. Ann Surg 2003;237:208-17.

7. Aoki T, Imamura H, Hasegawa K, et al. Sequential preoperative arterial and portal venous embolizations

Cite this article as: Guiu B, Herrero A, Panaro F. Liver venous deprivation: a bright future for liver metastases-but what about hepatocellular carcinoma? HepatoBiliary Surg Nutr 2021;10(2):270-272. doi: 10.21037/hbsn-21-7 in patients with hepatocellular carcinoma. Arch Surg 2004;139:766-74.

8. Chan A, Zhang WY, Chok K, et al. ALPPS Versus Portal Vein Embolization for Hepatitis-related Hepatocellular Carcinoma: A Changing Paradigm in Modulation of Future Liver Remnant Before Major Hepatectomy. Ann Surg 2019. [Epub ahead of print]. doi: 10.1097/ SLA.0000000000003433.

9. Panaro F, Giannone F, Riviere B, et al. Perioperative impact of liver venous deprivation compared with portal venous embolization in patients undergoing right hepatectomy: preliminary results from the pioneer center. Hepatobiliary Surg Nutr 2019;8:329-37.

10. Madoff DC, Odisio BC, Schadde E, et al. Improving the Safety of Major Resection for Hepatobiliary Malignancy: Portal Vein Embolization and Recent Innovations in Liver Regeneration Strategies. Curr Oncol Rep 2020;22:59.

11. Denys A, Lacombe C, Schneider F, et al. Portal vein embolization with N-butyl cyanoacrylate before partial hepatectomy in patients with hepatocellular carcinoma and underlying cirrhosis or advanced fibrosis. J Vasc Interv Radiol 2005;16:1667-74. 